\title{
Commentary: Is there more than one way to skin a pulmonary artery aneurysm?
}

Thomas M. Egan, MD, MSc, and John Ikonomidis, MD, PhD

\footnotetext{
From the Division of Cardiothoracic Surgery, Department of Surgery, School of Medicine, University of North Carolina at Chapel Hill, Chapel Hill, NC.

Disclosures: Authors have nothing to disclose with regard to commercial support.

This work was supported by the UNC Lung Transplant Research Fund, with generous contributions from the Ferguson family and John Doherty (to Dr Egan), and the National Heart, Lung, and Blood Institute Grant 2R01 HL102121 (to Dr Ikonomidis)

Received for publication Sept 2, 2019; revisions received Sept 2, 2019; accepted for publication Sept 3, 2019; available ahead of print Oct 31, 2019.

Address for reprints: Thomas M. Egan, MD, MSc, Department of Surgery, University of North Carolina at Chapel Hill, 3040 Burnett-Womack Bldg, Chapel Hill, NC 27599-7065 (E-mail: 1txtme@ med.unc.edu).

J Thorac Cardiovasc Surg 2020;159:2553-4

$0022-5223 / \$ 36.00$

Copyright (C) 2019 by The American Association for Thoracic Surgery

https://doi.org/10.1016/j.jtcvs.2019.09.033
}

Lung transplantation (LTX) has become an acceptable therapy for patients with end-stage lung disease. In this issue of the Journal, Schwarz and colleagues ${ }^{2}$ from the Vienna Lung Transplant Group report excellent outcomes using a technical solution in a rare subset of patients requiring LTX for pulmonary artery (PA) hypertension (PAH). Seven of 128 patients who underwent LTX for PAH had a pulmonary artery aneurysm (PAA), involving the main PA and often extending into the left and right PAs. This rare complication of PAH poses substantial problems for LTX and leads to the decision to perform heart-lung transplantation in some centers. We assume that these are patients with primary pulmonary hypertension. If so, this is a considerable and unique singlecenter experience in a country with a population of 9 million. In comparison, only 930 LTX procedures for primary PAH were performed in the United States (population $>300$ million) during the same time period (Figure 1). ${ }^{3}$ This discrepancy may be due to lung allocation policy differences and the ability of the Vienna group to choose recipients for donor lungs.

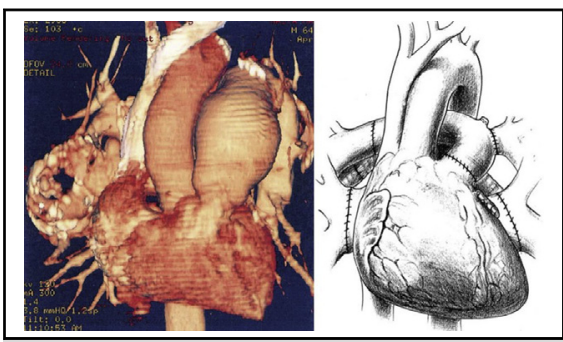

Replacing recipient pulmonary artery aneurysm with donor aorta as an alternative solution in the setting of lung transplantation.

Central Message

Pulmonary artery (PA) aneurysm, a rare complication of PA hypertension, poses a technical challenge at lung transplantation. The authors describe an elegant solution performed successfully 7 times among 128 PH patients undergoing LTX.

See Article page 2543.
Their clever solution to the technical challenge of a PAA may also be feasible because of allocation policy in a country with a single LTX center. Their well described and illustrated technique involves using the entire PA of the donor when the heart was not recovered. Interestingly, these PAAs were not associated with pulmonary valve regurgitation and so did not involve the valve annulus. There was no association between the ascending thoracic aortic diameter and the presence of a PAA, implying that the pathogenesis of PAAs in the setting of PAH may differ

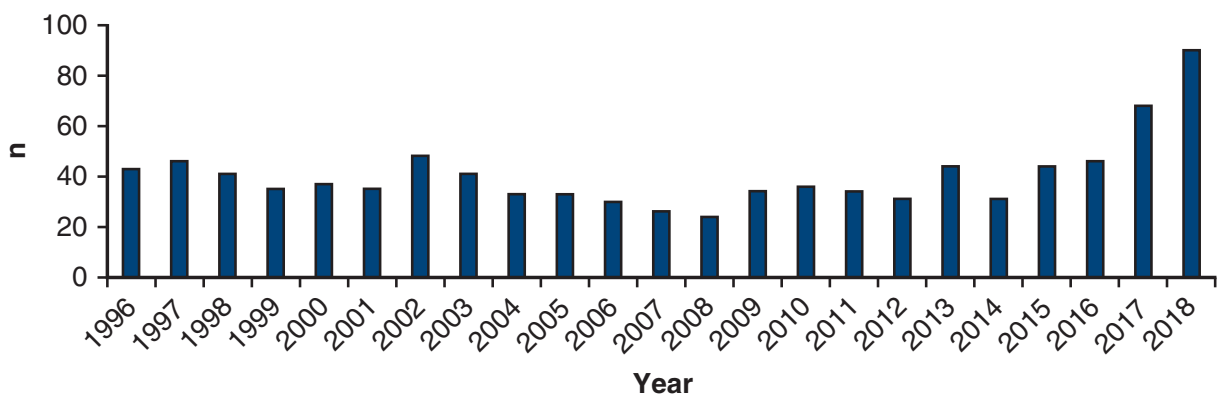

FIGURE 1. Number of lung transplants $(L T X)$ for primary pulmonary hypertension $(P P H)$ in the United States for the same time period as in the study reported by Schwarz and colleagues (1996-2018). The increase in 2017 likely reflects US allocation policy changes for patients with pulmonary artery hypertension, and that in 2018 likely reflects the wider geographic distribution of donor lungs outside of the local donor service area to more patients with higher lung allocation scores. ${ }^{4}$ 

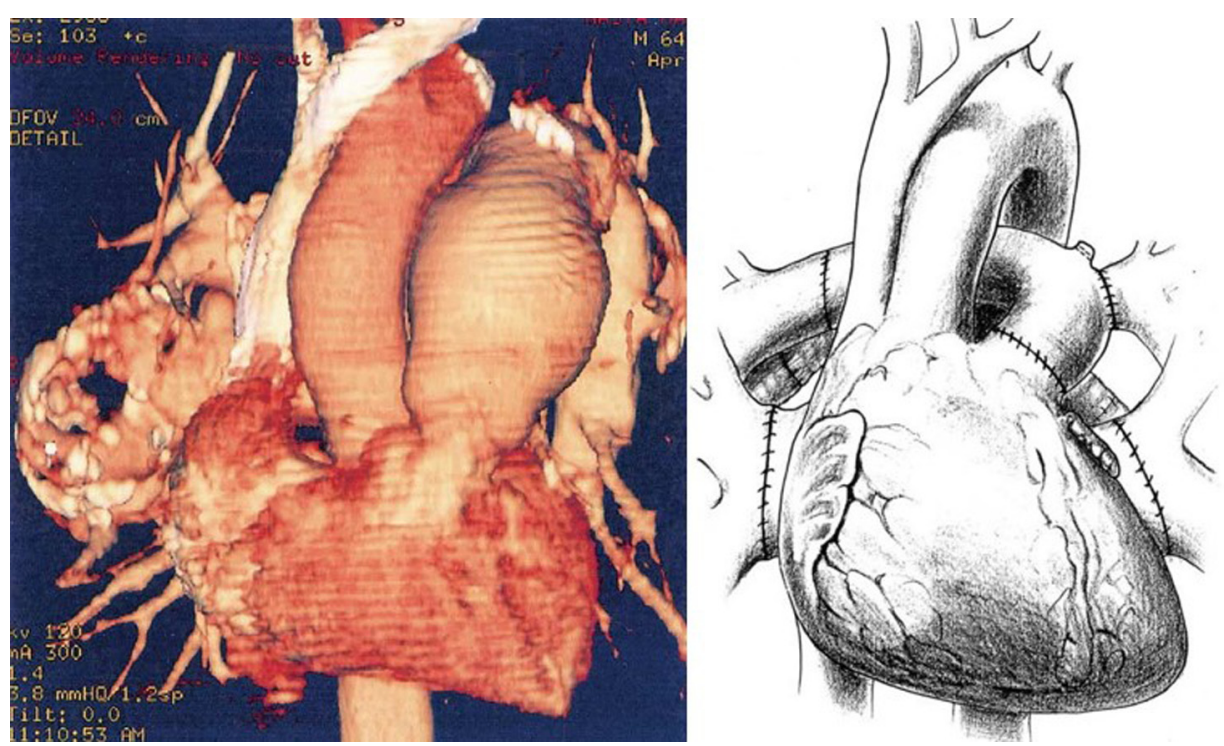

FIGURE 2. Replacing recipient pulmonary artery aneurysm with donor aorta as an alternative solution in the setting of lung transplantation. Reprinted with permission. ${ }^{1}$

from that for ascending thoracic aortic aneurysms, which often involve the annulus and cause aortic insufficiency.

Given that the ascending aorta and PA develop from a common truncus arteriosus, it stands to reason that the tendency for the PA to dilate is translatable to the ascending aorta as well. Much of the enthusiasm for performance of the Ross procedure in adults with bicuspid aortic valve disease waned as a result of this finding in pulmonary autografts translocated to the aortic position. ${ }^{4}$ The patients in this group all have the equivalent of PAH. Recent basic science studies have shown that the resident cells in the ascending aorta (and hence likely in the PA as well) have mechanoreceptor "set points" 5 that cause activation of cellular signaling and up-regulation of protease (in particular matrix metalloproteinase ${ }^{6}$ ) production causing unopposed proteolysis and weakening of the arterial wall. Despite this, although hypertension is a risk factor for aortic aneurysm formation, most hypertensive patients never develop aortic aneurysms, indicating that other mechanisms are involved that require further investigation.

Schwarz and colleagues describe an elegant technique that works very well in this rare situation. When the entire PA is not available, Force and coworkers described another solution that used the donor thoracic aortic arch and descending thoracic aorta to replace the recipient PAA $^{1}$ (Figure 2). Both techniques should be in the LTX surgeon's toolbox to address this rare complication of PAH.

\section{References}

1. Force SD, Lau CL, Moazami N, Trulock EP, Patterson GA. Bilateral lung transplantation and pulmonary artery reconstruction in a patient with chronic obstructive pulmonary disease and a giant pulmonary artery aneurysm. J Thorac Cardiovasc Surg. 2003;126:864-6.

2. Schwarz S, Benazzo A, Prosch H, Jaksch P, Klepetko W, Hoetzenecker K, Vienna Lung Transplant Group. Lung transplantation for pulmonary hypertension with giant pulmonary artery aneurysm. J Thorac Cardiovasc Surg. 2020;159:2543-50.

3. US Department of Health and Human Services. Health Resources Services Administration. Organ procurement and transplantation network. National data: 2019 OPTN transplant data. Available at: https://optn.transplant.hrsa.gov/data/ view-data-reports/build-advanced/. Accessed August 24, 2019.

4. de Sa M, Moshkovitz Y, Butany J, David TE. Histologic abnormalities of the ascending aorta and pulmonary trunk in patients with bicuspid aortic valve disease: clinical relevance to the Ross procedure. J Thorac Cardiovasc Surg. 1999;118:588-94.

5. Ruddy JM, Jones JA, Stroud RE, Mukherjee R, Spinale FG, Ikonomidis JS. Differential effects of mechanical and biological stimuli on matrix metalloproteinase promoter activation in the thoracic aorta. Circulation. 2009; 120(11 Suppl):S262-8

6. Jones JA, Ruddy JM, Bouges S, Zavadzkas JA, Brinsa TA, Stroud RE, et al. Alterations in membrane type- 1 matrix metalloproteinase abundance after the induction of thoracic aortic aneurysm in a murine model. Am J Physiol Heart Circ Physiol. 2010;299:H114-24. 